ISSN : $2450-766 X$

\title{
PENERAPAN METODE FUZZY MAMDANI UNTUK MEMPREDIKSI JUMLAH PRODUKSI KARET (STUDI KASUS: DATA PERSEDIAAN DAN PERMINTAAN PRODUKSI KARET PADA PTP NUSANTARA XIV (PERSERO) KEBUN AWAYA, TELUK ELPAPUTIH, MALUKU-INDONESIA)
}

\author{
D. L. Rahakbauw'1, F. J. Rianekuay², dan Y. A. Lesnussa ${ }^{3}$ \\ 1,2,3 Jurusan Matematika FMIPA Universitas Pattimura \\ Jalan Ir. M. Putuhena, Kampus Unpatti, Poka-Ambon 97233, Indonesia \\ 1lodewyik@gmail.com; 2filyarianekuay@yahoo.com; 3yopi_a_lesnussa@yahoo.com
}

\begin{abstract}
Good corporate management will determine the development of a company. In addition, the necessary production planning is also required to achieve maximum profit. This study uses data from PTP Nusantara XIV (Persero) Awaya Garden, Teluk Elpaputih, Maluku Province Indonesia, which is engaged in the production of raw rubber. This research uses Fuzzy Mamdani method to predict the amount of rubber production based on the demand data, inventory and production of rubber per day in April 2016. From the research result obtained the exact amount of rubber production with the percentage of truth value equal to $87,83 \%$ and the resultant error is $12,17 \%$.
\end{abstract}

Keywords : Demand, Fuzzy Logic Mamdani Method, Inventory, Production.

\begin{abstract}
ABSTRAK
Manajemen perusahan yang baik akan menentukan berkembangnya sebuah perusahaan. Selain itu, diperlukan juga perencanaan produksi yang tepat agar dapat dicapai keuntungan maksimal. Dalam memproduksi diperlukan perencanaan produksi yang tepat. Penelitian ini menggunakan data dari PTP Nusantara XIV (Persero) Kebun Awaya/Teluk Elpaputih, yang bergerak dalam bidang produksi karet mentah. Penelitian ini menggunakan metode Fuzzy Mamdani untuk meramalkan jumlah produksi karet berdasarkan data permintaan, persediaan dan produksi karet per hari pada bulan April 2016. Dari hasil penelitian diperoleh jumlah produksi karet yang tepat dengan presentase nilai kebenaran sebesar $87,83 \%$ dan error yang dihasilkan yaitu $12,17 \%$.
\end{abstract}

Kata kunci $\quad$ : Permintaan, Logika Fuzzy Metode Mamdani, Persediaan, Produksi. 


\section{PENDAHULUAN}

Persaingan pasar dalam dunia industri sangat penting dibutuhkan oleh sebuah perusahaan khususnya PTP Nusantara XIV (Persero) Kebun Awaya/Teluk Elpaputih yang bergerak dalam bidang pengolahan karet. Produksi karet dalam waktu yang tepat dan dalam jumlah yang tepat merupakan sesuatu yang diinginkan oleh perusahaan tersebut. Namun, dalam menentukan jumlah produksi karet di waktu yang akan datang tidaklah mudah. Banyaknya faktor yang menjadi kendala dalam kebijakan untuk dapat menentukan jumlah karet yang akan diproduksi. Sehingga, sasaran produksi tidak tercapai karena usia tanaman dan populasi yang tidak standar berpengaruh terhadap produktivitas tanaman di kebun Awaya/Teluk Elpaputih. Sasaran tersebut berpengaruh terhadap faktor-faktor antara lain permintaan maksimum, permintaan minimum, persediaan maksimum, persediaan minimum, produksi maksimum, dan produksi minimum.

Logika fuzzy merupakan ilmu yang mempelajari mengenai ketidakpastian. Logika fuzzy juga mampu untuk memetakan suatu ruang input kedalam suatu ruang output dengan tepat. Dalam teori sistem fuzzy dikenal suatu konsep sistem fuzzy yang digunakan dalam proses prediksi. Salah satu metode yang digunakanya itu metode mamdani. Metode mamdani adalah metode yang juga sering di kenal dengan metode MAX-MIN atau MAX-PRODUCT. Proses prediksi metode mamdani ada empat tahap yaitu pembentukan himpunan fuzzy (pembentukan variabel input maupun variabel output dibagi menjadi satu atau lebih himpunan fuzzy), aplikasi fungsi implikasi (fungsi implikasi ditentukan dari nilai yang berupa himpunan fuzzy yang digunakan sebagai implikasi yaitu nilai MIN atau nilai yang paling terendah), komposisi aturan (cara-cara yang digunakan untuk menentukan penilaian himpunan fuzzy), defuzzification (tahap terakhir untuk proses mengolah suatu himpunan fuzzy yang diperoleh dari komposisi aturan fuzzy untuk menghasilkan output berupa suatu bilangan pada domain himpunan fuzzy tersebut). Di dalam perhitungan logika fuzzy terdapat beberapa metode, yaitu metode Sugeno, metode Mamdani, dan metode Tsukamoto. Masing-masing metode memiliki cara dan hasil perhitungan yang berbeda. Dalam kasus ini, masalah yang timbul adalah bagaimana cara menerapkan metode fuzzy Mamdani dan memprediksi jumlah produksi karet berdasarkan data persediaan dan jumlah permintaan.

\section{METODE PENELITIAN}

Ada dua tipe variabel yang digunakan dalam penelitian ini yaitu variabel input dan variabel output dimana variabel input adalah data persediaan yang mempunyai tiga himpunan fuzzy (Sedikit, Sedang, Banyak) dan jumlah permintaan juga memiliki tiga himpunan fuzzy (Rendah, Sedang, Tinggi) sedangkan variabel output adalah jumlah produksi yang juga mempunyai tiga himpunan fuzzy (Sedikit, Sedang, Banyak).

Data yang digunakan dalam penelitian ini berupa data sekunder yang diperoleh dari PTP Nusantara XIV (Persero) Kebun Awaya/Teluk Elpaputih yaitu: data permintaan, persediaan dan data produksi per hari dalam jangka waktu satu bulan (April 2016). Dimana data-data tersebut kemudian 
digunakan untuk menentukan jumlah produksi karet pada perusahaan tersebut. Data-data tersebut merupakan data dengan satuan liter dan data-data tersebut dapat dilihat pada Tabel 1.

Tabel 1 : Data Permintaan, data Persediaan dan data Produksi

\begin{tabular}{|c|c|c|c|c|}
\hline No & Tanggal & $\begin{array}{c}\text { Permi } \\
\text { ntaan }\end{array}$ & $\begin{array}{c}\text { Perse } \\
\text { diaan }\end{array}$ & $\begin{array}{c}\text { Produ } \\
\text { ksi }\end{array}$ \\
\hline 1 & $01 / 4 / 2016$ & 5164 & 774 & 5428 \\
\hline 2 & $02 / 4 / 2016$ & 2979 & 700 & 4393 \\
\hline 3 & $04 / 4 / 2016$ & 3517 & 1142 & 3928 \\
\hline 4 & $05 / 4 / 2016$ & 2227 & 628 & 5545 \\
\hline 5 & $06 / 4 / 2016$ & 3043 & 1452 & 4020 \\
\hline 6 & $07 / 4 / 2016$ & 4777 & 1018 & 4741 \\
\hline 7 & $08 / 4 / 2016$ & 3148 & 1147 & 6769 \\
\hline 8 & $09 / 4 / 2016$ & 5766 & 1419 & 4951 \\
\hline 9 & $11 / 4 / 2016$ & 7493 & 1332 & 5501 \\
\hline 10 & $12 / 4 / 2016$ & 4935 & 863 & 5369 \\
\hline 11 & $13 / 4 / 2016$ & 2049 & 1152 & 6029 \\
\hline 12 & $14 / 4 / 2016$ & 4778 & 617 & 4887 \\
\hline 13 & $15 / 4 / 2016$ & 6176 & 711 & 5775 \\
\hline 14 & $16 / 4 / 2016$ & 5821 & 567 & 5161 \\
\hline 15 & $18 / 4 / 2016$ & 6632 & 1237 & 6496 \\
\hline
\end{tabular}

\begin{tabular}{|c|c|c|c|c|}
\hline No & Tanggal & $\begin{array}{c}\text { Permi } \\
\text { ntaan }\end{array}$ & $\begin{array}{c}\text { Perse } \\
\text { diaan }\end{array}$ & $\begin{array}{c}\text { Produ } \\
\text { ksi }\end{array}$ \\
\hline 16 & $19 / 4 / 2016$ & 2847 & 1223 & 3867 \\
\hline 17 & $20 / 4 / 2016$ & 7198 & 927 & 4948 \\
\hline 18 & $21 / 4 / 2016$ & 2360 & 1285 & 3719 \\
\hline 19 & $22 / 4 / 2016$ & 2925 & 1249 & 6705 \\
\hline 20 & $23 / 4 / 2016$ & 4861 & 1175 & 4768 \\
\hline 21 & $25 / 4 / 2016$ & 6510 & 1248 & 5433 \\
\hline 22 & $26 / 4 / 2016$ & 5070 & 926 & 4876 \\
\hline 23 & $27 / 4 / 2016$ & 7147 & 695 & 6180 \\
\hline 24 & $28 / 4 / 2016$ & 4254 & 667 & 4460 \\
\hline 25 & $29 / 4 / 2016$ & 4971 & 550 & 4785 \\
\hline
\end{tabular}

Sumber: PTP Nusantara XIV (Persero) Kebun Awaya/Teluk Elpaputih

\section{HASIL DAN PEMBAHASAN}

Dalam penelitian ini, penyelesaian proses perhitungan manual dengan menggunakan Penerapan Logika Fuzzy Metode Mamdani terdapat empat tahap yang harus dilakukan yaitu Menentukan Himpunan Fuzzy, Aplikasi Fungsi Implikasi, Komposisi Antar Aturan, Penegasan (deffuzyfication). Proses Perhitungan manual dilakukan terlebih dahulu dengan menggunakan satu contoh kasus agar dapat membuktikan kesamaan pada tahap akhir yaitu penegasan (deffuzyfication) supaya mendapatkan output yang sama. Untuk mendapatkan output selanjutnya untuk kasus yang lain dilakukan dengan Software Matlab dengan menginput data permintaan dan data persediaan dalam kolom input pada Rule View.

\section{Contoh Kasus 1:}

PTP Nusantara XIV (Persero) Kebun Awaya/Teluk Elpaputih dalam waktu satu hari yaitu tanggal 01/04/2016 ingin mengetahui jumlah produksi karet yang akan diproduksi menggunakan Penerapan Logika Fuzzy Metode Mamdani berdasarkan data pada Tabel 1, dengan permintaan sebesar 5164 Liter dan persediaan sebesar 774 Liter. Kira-kira Berapa jumlah produksi karet yang akan diproduksi? 


\section{Langkah 1 : Menentukan Himpunan Fuzzy}

Dalam menentukan himpunan fuzzy terlebih dahulu harus mencari derajat keanggotaan dari fungsi keanggotaan yang direpresentasikan dengan representasi kurva segitiga. Variabel permintaan telah didefinisikan pada tiga himpunan fuzzy yaitu RENDAH, SEDANG dan TINGGI setiap himpunan Fuzzy memiliki interval derajat keanggotaan. Berikut adalah gambar fungsi keanggotaan pada variabel permintaan 5164 Liter dan persediaan 774 Liter.

Permintaan 5164 liter termasuk kedalam himpunan fuzzy SEDANG dan derajat keanggotaan sesuai fungsi berikut :

$$
\mu[x] \text { SEDANG }=\left\{\begin{array}{cc}
0 & ; x \leq 3360 \\
\frac{x-3360}{5200-3360} ; & 3360 \leq x \leq 5200 \\
\frac{7040-x}{7040-5200} ; & 5200 \leq x \leq 7040
\end{array}\right.
$$

Diketahui :

$$
\mu[x]=5164, \quad \mathrm{a}=3360, \quad \mathrm{~b}=5200, \quad \mathrm{c}=7040
$$

Sehingga diperoleh:

$$
\mu[5164] S E D A N G=\frac{5164-3360}{5200-3360}=\frac{1804}{1840}=0,98
$$

$$
\begin{gathered}
\mu[5164] \text { SEDANG }=0,98 \\
\mu[5164] \text { RENDAH }=0,00 \\
\mu[5164] \text { TINGGI }=0,00
\end{gathered}
$$

Yang berarti bahwa permintaan karet tersebut dikatakan SEDANG dengan derajat keanggotaan $=0,98$ atau 98\%. Untuk variabel persediaan didefenisikan pada tiga himpunan fuzzy, yaitu SEDIKIT, SEDANG, BANYAK. Setiap himpunan fuzzy memiliki interval fungsi keanggotaan. Berikut adalah gambar fungsi keanggotaan pada variabel persediaan 774 liter. Persediaan 774 liter termasuk kedalam himpunan fuzzy SEDIKIT dan SEDANG dengan derajat keanggotaan sesuai fungsi berikut :

Diketahui :

$$
\begin{aligned}
\mu[x] \text { SEDIKIT }= & \left\{\begin{array}{l}
0 \quad ; x \leq 100 \text { atau } x \geq 991 \\
\frac{x-100}{496-100} ; 100 \leq x \leq 496 \\
\frac{991-x}{991-496} ; 496 \leq x \leq 991
\end{array}\right. \\
\mu[x] \text { SEDANG } & =\left\{\begin{array}{l}
0 \quad ; x \leq 600 \text { atau } x \geq 1400 \\
\frac{x-600}{1000-600} ; 600 \leq x \leq 1000 \\
\frac{1400-x}{1400-1000} ; 1000 \leq x \leq 1400
\end{array}\right.
\end{aligned}
$$

1. $\mu[x]=774$

$$
\begin{aligned}
& a=100, b=496, c=991 \\
& \mu[774] \text { SEDIKIT }=\frac{991-774}{991-496} \\
&=\frac{217}{495} \\
&=0,438 \approx 0,44
\end{aligned}
$$


2. $\mu[x]=774$

$$
\begin{aligned}
& a=600, b=1000, c=1400 \\
& \mu[774] \text { SED ANG }=\frac{774-600}{1000-600} \\
&=\frac{174}{400} \\
&=0,435 \approx 0,44
\end{aligned}
$$

Maka, diperoleh :

$$
\begin{aligned}
& \mu[774] \text { SEDANG }=0,44 \\
& \mu[7744] \text { SEDIKIT }=0,44 \\
& \mu[5164] \text { BANYAK }=0,00
\end{aligned}
$$

Yang berarti bahwa persediaan karet tersebut dikatakan SEDANG dan SEDIKIT dengan derajat keanggotaan $=0,44$ atau $44 \%$

\section{Langkah 2 : Aplikasi Fungsi Implikasi}

Fungsi implikasi yang digunakan dalam proses ini adalah fungsi MIN, yaitu dengan mengambil derajat keanggotaan minimum dari variabel input sebagai outputnya. Berdasarkan aturan-aturan yang sesuai dengan fungsi implikasi yaitu ada 9 aturan tetapi yang digunakan yaitu dua aturan yaitu [R4] dan [R5] sebagai berikut:

[R4] : Jika Permintaan adalah SEDANG dan Persediaan adalah SEDIKIT Maka produksi adalah SEDANG.

[R5] : Jika Permintaan adalah SEDANG dan Persediaan adalah SEDANG Maka produksi adalah SEDANG.

Penyelesaian :

[R4] : Jika Permintaan adalah SEDANG dan Persediaan adalah SEDIKIT Maka produksi adalah SEDANG.

$$
\begin{gathered}
\alpha \text { predikat }_{1}=\mu_{\text {PmtSEDANG }} \cap \mu_{\text {PSdSEDIKIT }} \\
=\min \left(\mu_{\text {PmtSEDANG }}(0,98), \mu_{\text {PSASEDIKIT }}(0,44)\right) \\
=\min (0,98,0,44) \\
=0,44
\end{gathered}
$$

[R5] : Jika Permintaan adalah SEDANG dan Persediaan adalah SEDANG Maka produksi adalah SEDANG.

$$
\begin{aligned}
\alpha-\text { predikat }_{2}=\mu_{P m t S E D A N G} \cap \mu_{P S d S E D A N G} \\
=\min \left(\mu_{P m t S E D A N G}(0,98), \mu_{P S d S E D A N G}(0,98)\right) \\
=\min (0,98,0,98) \\
=0,98
\end{aligned}
$$


Tabel 2 : Aplikasi Fungsi Implikasi untuk Permintaan 5164 Liter dan Persediaan 774 Liter

\begin{tabular}{|c|c|c|c|}
\hline \multirow{2}{*}{ Persediaan } & \multicolumn{3}{|c|}{ Permintaan } \\
\cline { 2 - 4 } & RENDAH & SEDANG & TINGGI \\
\hline SEDIKIT & 0,00 & 0,98 & 0,00 \\
\hline SEDANG & 0,00 & 0,44 & 0,00 \\
\hline BANYAK & 0,00 & 0,00 & 0,00 \\
\hline
\end{tabular}

\section{Langkah 3 : Komposisi Aturan}

Komposisi aturan menggunakan fungsi MAX, sehingga Pada metode ini solusi himpunan fuzzy diperoleh dengan cara mengambil nilai maksimum aturan, kemudian menggunakannya untuk memodifikasi daerah fuzzy. Komposisi aturan merupakan kesimpulan secara keseluruhan dengan mengambil tingkat keanggotaan maksimum dari tiap konsekuen aplikasi fungsi implikasi dengan menggabungkan dari semua kesimpulan masing-masing aturan, sehingga akan didapat daerah solusi fuzzy sebagai berikut :

$$
\begin{aligned}
\mu_{S f}(x)=\operatorname{maks} & \left\{\mu_{P \operatorname{miSEDANG}}(0,98), \mu_{\text {PSdSEDIKIT }}(0,44)\right\} \\
& =\operatorname{maks}\{0,98,0,44\} \\
& =0,98
\end{aligned}
$$

Titik potong antar aturan yaitu [R4] dan [R5] ketika $\mu_{\text {ProduksiSEDIKIT }}(x)=0,44$ maka ditentukan nilai $\mathrm{x}$ berikut:

$$
\begin{aligned}
& \frac{4750-x}{1400}=0,98 \\
x \quad & 4750-0,98(1400) \\
& x=4722
\end{aligned}
$$

Ketika $\mu_{\text {ProduksiSEDANG }}(x)=0,98$ maka ditentukan nilai $\mathrm{x}$ berikut:

$$
\begin{gathered}
\frac{x-3350}{1400}=0,98 \\
x=0,98(1400)+3350 \\
x=3378
\end{gathered}
$$

Sehingga didapat fungsi keanggotaan daerah solusi sebagai berikut:

$$
\mu_{\text {Produksi }}=\left\{\begin{array}{lr}
\frac{x-38}{1400} ; & ; 0 \leq x \leq 4722 \\
0,44 & ; 4722 \leq x \leq 4722 \\
\frac{4750-x}{1400} ; 4750 \leq x \leq 6150
\end{array}\right.
$$

\section{Langkah 4: Penegasan (Defuzzyfication)}

Langkah terakhir dalam proses ini adalah deffuzifikasi atau disebut juga tahap penegasan, yaitu untuk mengubah himpunan fuzzy menjadi bilangan riil. Input dari proses penegasan ini adalah suatu himpunan fuzzy yang diperoleh dari komposisi aturan-aturan fuzzy, sedangkan output yang dihasilkan merupakan suatu bilangan pada domain himpunan fuzzy tersebut. Deffuzifikasi yang digunakan dalam menentukan jumlah produksi pada kasus ini adalah dengan Metode Centroid. Berikut adalah perhitungan deffuzifikasi dengan Metode Centroid : 


$$
\begin{aligned}
X & =\frac{\int_{0}^{4722}(0,98) x d x+\int_{3350}^{4722}\left(\frac{x-3350}{1400}\right) x d x+\int_{4722}^{4750}(0,44) x d x+\int_{4750}^{6150}\left(\frac{4750-x}{1400}\right) x d x}{\int_{0}^{4722}(0,98) d x+\int_{3350}^{4722}\left(\frac{x-3350}{1400}\right) d x+\int_{4722}^{4750}(0,44) d x+\int_{4750}^{6150}\left(\frac{4750-x}{1400}\right) d x} \\
& =\frac{1056875,775}{223,9143591} \\
& =4720
\end{aligned}
$$

Sehingga dari Penerapan Logika Fuzzy Metode Mamdani pada hasil perhitungan manual untuk contoh kasus 1 dengan perhitungan toolbox matlab untuk memprediksi penentuan jumlah produksi karet dalam contoh kasus 1 dengan permintaan sebesar 5164 Liter dan persediaan 774 Liter sehingga jumlah produksi yang akan diproduksi pada tanggal 01/04/2016 yaitu 4720 Liter. Pada contoh kasus ini dapat dilihat outputnya pada Rule view perhitungan toolbox matlab menggunakan software matlab pada Gambar 1 ..

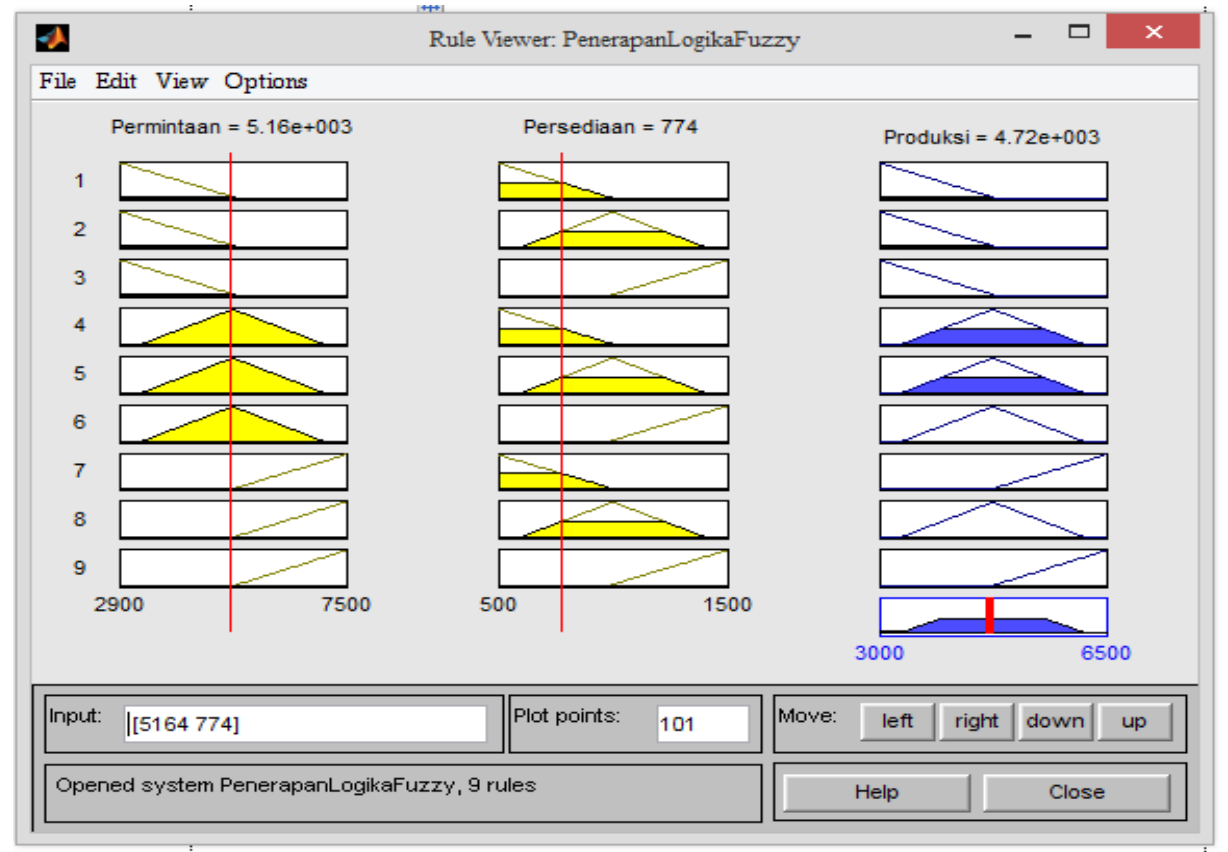

Gambar 1 : Rule View (Hasil Optimasi/Defuzzifikasi)

\section{Perhitungan Mean Precentage Error (MPE)}

Dalam melakukan perhitungan dengan menggunakan Mean Precentage Error (MPE) pada kasus ini, data produksi dari perusahaan akan dijadikan sebagai $a_{t}$ sedangkan data produksi hasil berdasarkan fuzzy mamdani akan dijadikan sebagai $\tilde{a}_{t}$. Hasil perhitungannya dapat dilihat pada Tabel 3.

Tabel 3. Perhitungan MPE

\begin{tabular}{|l|l|c|c|l|l|}
\hline No & Tanggal & $\begin{array}{c}a_{t} \\
\text { (Prd) }\end{array}$ & $\begin{array}{c}\tilde{a}_{t} \\
\text { (Fuzzy) }\end{array}$ & Error & $\frac{\left(a_{t}-\tilde{a}_{t}\right)}{a_{t}} x 100 \%$ \\
\hline 1 & $01 / 4 / 2016$ & 5428 & 4720 & 708 & 13.04348 \\
\hline 2 & $02 / 4 / 2016$ & 4393 & 3650 & 743 & 16.91327 \\
\hline
\end{tabular}

\begin{tabular}{|l|l|c|c|c|l|}
\hline No & Tanggal & $\begin{array}{c}a_{t} \\
(\text { Prd) }\end{array}$ & $\begin{array}{c}\tilde{a}_{t} \\
\text { (Fuzzy) }\end{array}$ & Error & $\mid \frac{\left(a_{t}-\tilde{a}_{t}\right)}{a_{t}} x 1000$ \\
\hline 16 & $19 / 4 / 2016$ & 3867 & 3700 & 167 & 4.31859 \\
\hline 17 & $20 / 4 / 2016$ & 4948 & 4810 & 138 & 2.78901 \\
\hline
\end{tabular}




\begin{tabular}{|c|c|c|c|c|c|}
\hline 3 & $04 / 4 / 2016$ & 3928 & 3870 & 58 & 1.47658 \\
\hline 4 & 05/4/2016 & 5545 & 3610 & 1935 & 34.8963 \\
\hline 5 & 06/4/2016 & 4020 & 3590 & 430 & 10.69652 \\
\hline 6 & 07/4/2016 & 4741 & 4640 & 101 & 2.13035 \\
\hline 7 & 08/4/2016 & 6769 & 3640 & 3129 & 46.22544 \\
\hline 8 & 09/4/2016 & 4951 & 4880 & 71 & 1.43405 \\
\hline 9 & $11 / 4 / 2016$ & 5501 & 5480 & 21 & 0.38175 \\
\hline 10 & $12 / 4 / 2016$ & 5369 & 4670 & 699 & 13.01918 \\
\hline 11 & $13 / 4 / 2016$ & 6029 & 3640 & 2389 & 39.62515 \\
\hline 12 & 14/4/2016 & 4887 & 4640 & 247 & 5.05423 \\
\hline 13 & $15 / 4 / 2016$ & 5775 & 5050 & 725 & 12.55411 \\
\hline 14 & $16 / 4 / 2016$ & 5161 & 4900 & 261 & 5.05716 \\
\hline 15 & $18 / 4 / 2016$ & 6496 & 5130 & 1366 & 21.02833 \\
\hline
\end{tabular}

\begin{tabular}{|l|l|l|l|l|l|}
18 & $21 / 4 / 2016$ & 3719 & 3660 & 59 & 1.58645 \\
\hline 19 & $22 / 4 / 2016$ & 6705 & 3680 & 3025 & 45.11559 \\
\hline 20 & $23 / 4 / 2016$ & 4768 & 4640 & 128 & 2.68456 \\
\hline 21 & $25 / 4 / 2016$ & 5433 & 5160 & 273 & 5.02485 \\
\hline 22 & $26 / 4 / 2016$ & 4876 & 4710 & 166 & 3.40443 \\
\hline 23 & $27 / 4 / 2016$ & 6180 & 5350 & 830 & 13.43042 \\
\hline 24 & $28 / 4 / 2016$ & 4460 & 4440 & 20 & 0.44843 \\
\hline 25 & $29 / 4 / 2016$ & 4785 & 4690 & 95 & 1.98537 \\
\hline
\end{tabular}

Maka ,

$$
\begin{aligned}
M P E & =\frac{\sum_{t=1}^{n} \frac{a_{t}-\hat{a}_{t}}{a_{t}} \times 100 \%}{n} \\
& =\frac{304,32359 \%}{25} \\
& =12,17294 \%
\end{aligned}
$$

Sehingga,

$$
100 \%-12,17294 \%=87,82706 \%
$$

Berdasarkan hasil pengujian tentang perhitungan prediksi produksi dengan penerapan Logika fuzzy mamdani menggunakan software matlab, maka dapat diketahui dari 25 data yang memenuhi permintaan dengan nilai Presentase sebesar $87,82706 \%$. sedangkan nilai rata-rata dari selisih antar produksi dan prediksi produksi menggunakan metode fuzzy mamdani adalah sebesar 17.784 dengan rata-rata presentase kesalahan dari metode mamdani adalah sebesar $12,17294 \%$. Oleh karena tingkat kebenaran dari perhitungan menggunakan metode mamdani ini adalah 87,82706\% maka dapat disimpulkan bahwa Penerapan Metode Fuzzy Mamdani dapat digunakan untuk memprediksi jumlah produksi karet yang akan diproduksi pada PTP Nusantara XIV (Persero) KebunAwaya/Teluk Elpaputih. 


\section{KESIMPULAN}

Berdasarkan rumusan masalah, pembahasan dan hasil penelitian mengenai penentuan jumlah produksi karet dalam satuan Liter per hari berdasarkan permintaan dan persediaan karet, maka dapat diambil kesimpulan bahwa:

1. Penerapan Logika Fuzzy dengan Metode Mamdani efektif diterapkan dalam aplikasi software Matlab untuk membantu pihak perusahaan dalam memprediksi penentuan jumlah produksi karet dalam satuan Liter per hari pada PTP Nusantara XIV (Persero) Kebun Awaya/Teluk Elpaputih, Kabupaten Maluku Tengah. Dari hasil uji coba prediksi dengan aplikasi software Matlab diperoleh presentase nilai kebenaran sebesar $87,82706 \%$ yang artinya mendekati sangat baik dalam penentuan jumlah produksi karet pada PTP Nusantara XIV (Persero) Kebun Awaya/Teluk Elpaputih. Serta tingkat error yang dihasilkan yaitu 12,17294\% dari tingkat error $100 \%$.

2. Berdasarkan hasil perhitungan jumlah produksi karet menggunakan Penerapan Logika Fuzzy Mamdani pada software Matlab yang kemudian hasilnya dibandingkan dengan data penelitian yang diperoleh dari PTP Nusantara XIV (Persero) Kebun Awaya/TelukElpaputih, Kabupaten Maluku Tengah. Maka, dapat dikatakan bahwa Penerapan Logika Fuzzy Mamdani dapat dipakai sebagai alat peramalan yang baik untuk memprediksi penentuan jumlah produksi karet berdasarkan banyaknya permintaan dan persediaan karet pada PTP Nusantara XIV (Persero) Kebun Awaya/Teluk Elpaputih.

\section{DAFTAR PUSTAKA}

[1] Klir George J., Clair Ute St., \& Yuan Bo, Fuzzy Set Theory Foundations And Aplications, New Jersey Pretice Hall International, Inc., 1997.

[2] Kusumadewi S. \& Purnomo H., Aplikasi Logika Fuzzy Untuk Pendukung Keputusan, 2004, Graha IImu, Yogyakarta,

[3] Djunaedi Much, Setiawan E., Andistas, \& Fajar W., Penentuan Jumlah Produksi Dengan Aplikasi Metode Fuzzy Mamdani. Jurnal IImiah Teknik Industri 4 : hal. 95-104. 2005, Jurusan Teknik Industri Universitas Muhammadiyah Surakarta, Surakarta.

[4] Sivanandam S. N., Deepa S. N., \& Sumathi, S, Introduction To Fuzzy Logic Using Matlab, Springer, 2007, Verlag, Berlin, Heidelberg.

[5] Sutojo T., Mulyanto E., \& Suhartono V., Kecerdasan Buatan, Andi Offset, 2011, Yogyakarta. 